\title{
An accelerated hybrid projection method with a self-adaptive step-size sequence for solving split common fixed point problems
}

\author{
Zheng Zhou ${ }^{1}$, Bing Tan ${ }^{1}$, and Songxiao $\operatorname{Li}^{1}$ \\ ${ }^{1}$ University of Electronic Science and Technology of China
}

April 27, 2020

\begin{abstract}
This paper attempts to focus on the split common fixed point problem for demicontractive mappings. We give an accelerated hybrid projection algorithm which combines the hybrid projection method and the inertial technique. The strong convergence theorems of this algorithm are obtained under mild conditions by a self-adaptive step-size sequence, which does not need prior knowledge of operator norms. Some numerical experiments in infinite Hilbert space are provided to illustrate the reliability and robustness of the algorithm and also to compare it with existing ones.
\end{abstract}

Hosted file zhou-scfpp-wiley.pdf available at https://authorea.com/users/315224/articles/445591-an-acceleratedhybrid-projection-method-with-a-self-adaptive-step-size-sequence-for-solving-split-common-fixed-point-problems

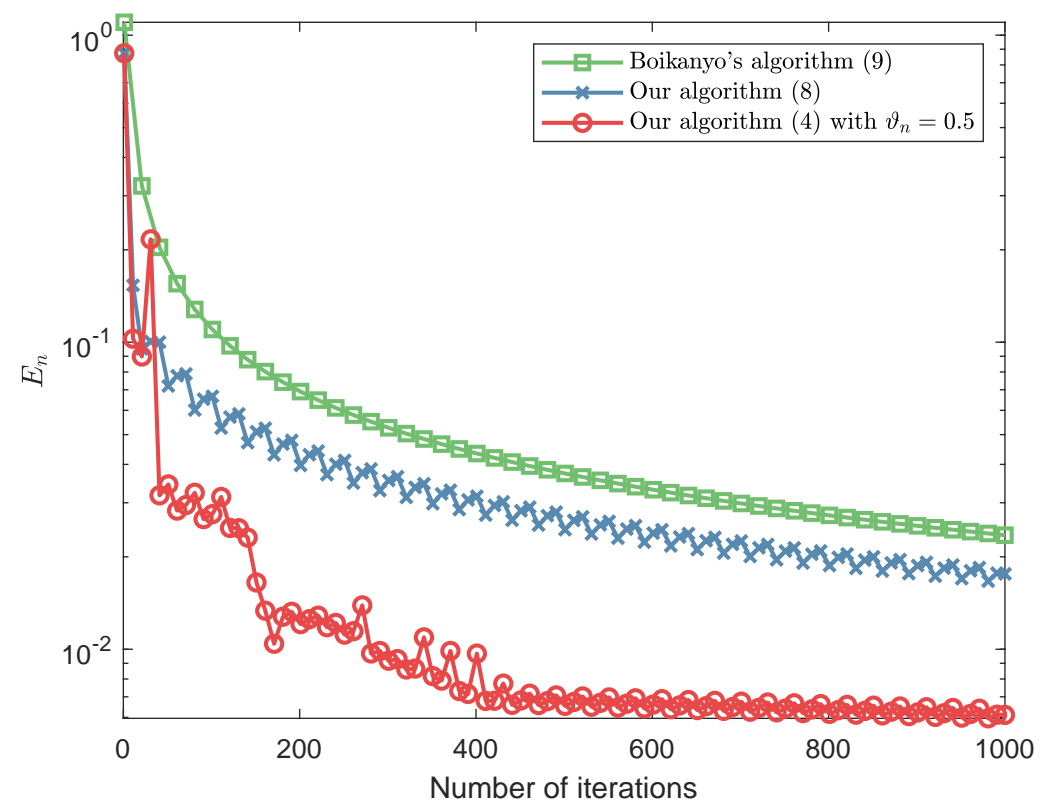



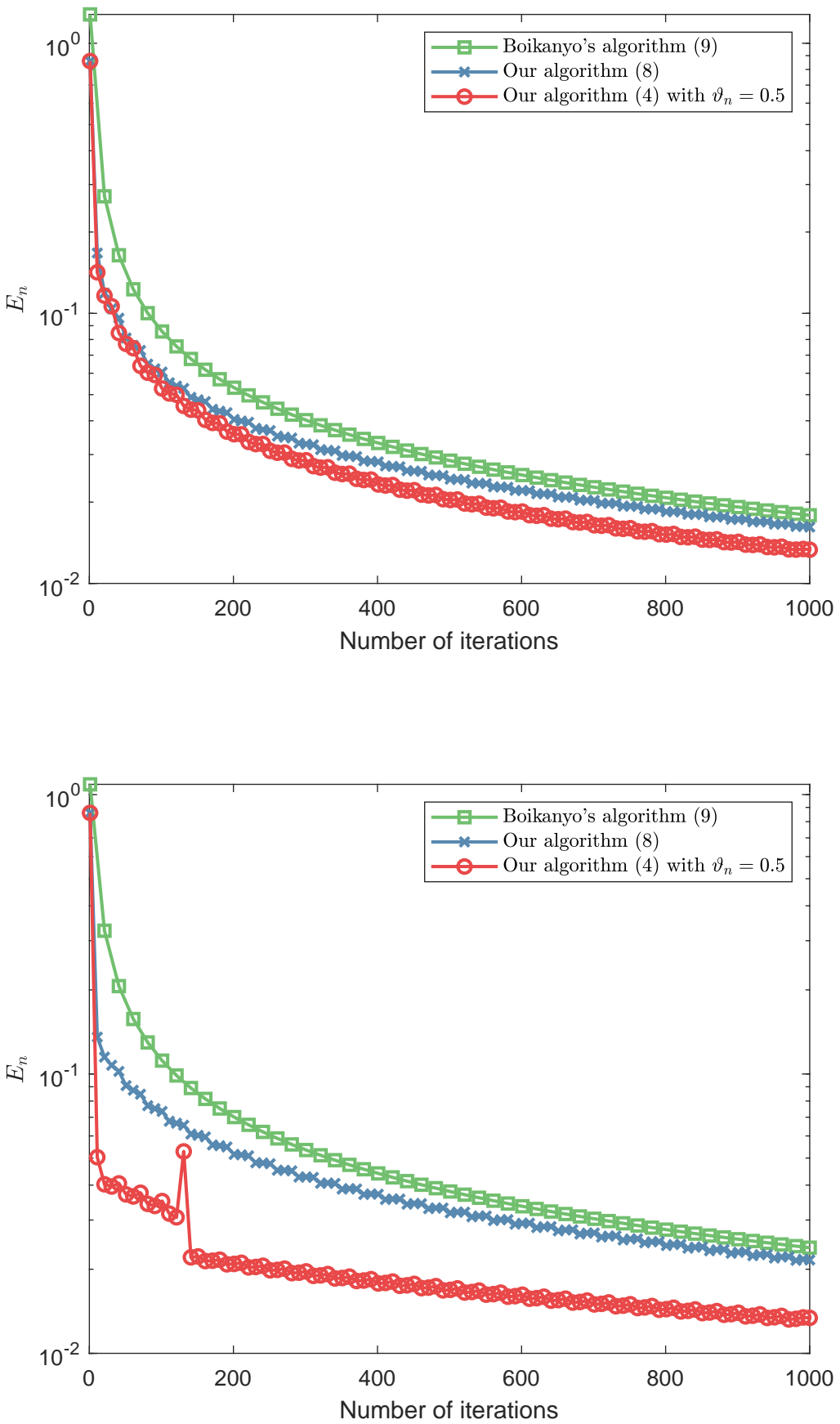

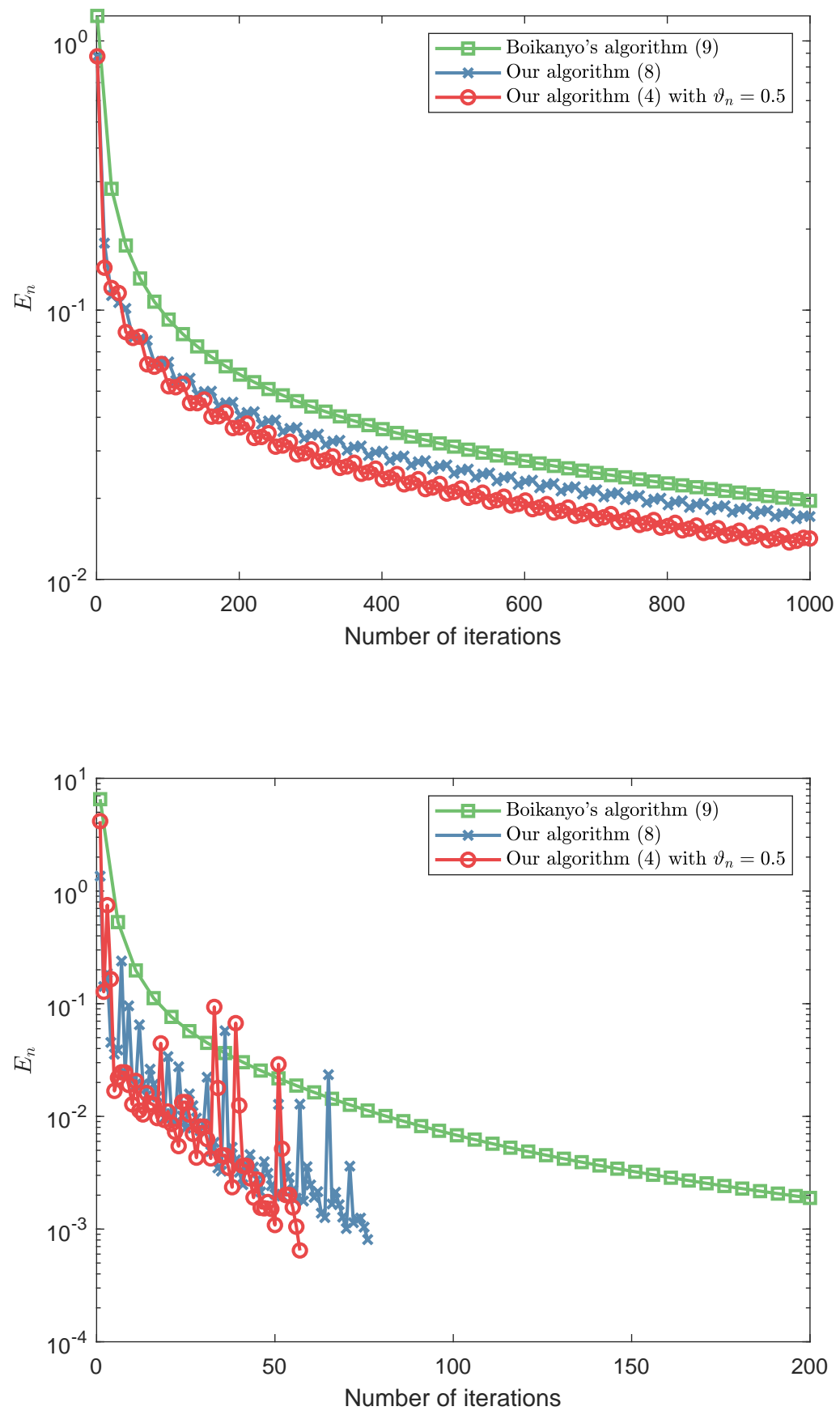

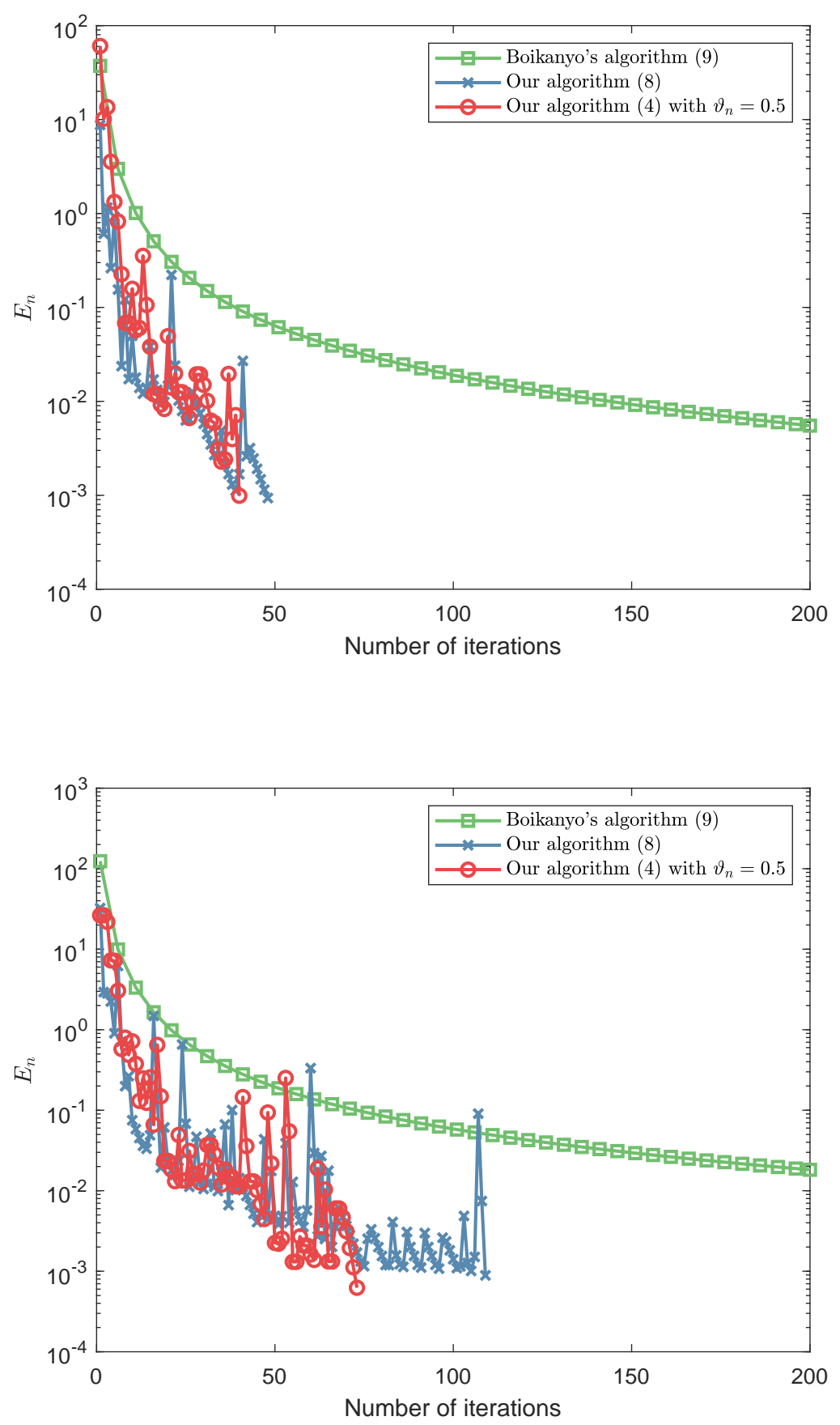


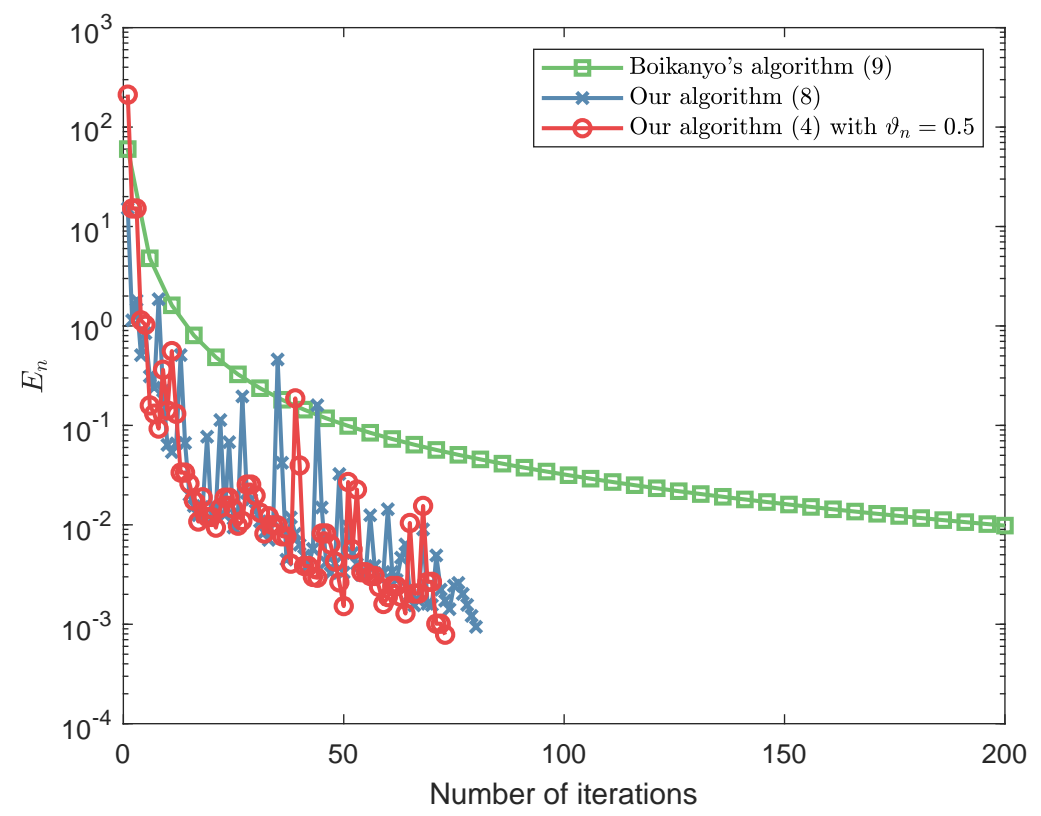

